\title{
Intervention in Online Writing Instruction: An Action-theoretical Perspective
}

Julie Stella, Michael Corry

\begin{abstract}
This analysis argues for an interwoven perspective of motivation, engagement, agency, and action in Online Writing Instruction (OWI) compiled from shared elements of empirical research in online education, writing instruction, and especially student academic engagement in traditional classrooms, where the research domain is comparatively mature. Engagement is the common element shared by these domains. In online education research, engagement is sometimes understood through intentional student actions. In writing instruction, engagement is commonly understood through human agency. In academic settings, engagement can be seen as a foundational part of Self-Determination Theory, which is comprised of cognitive, behavioral, and emotional engagement (Deci and Ryan, 1985). Educators often find measures of engagement valuable because they are reliable predictors of student outcomes, and they suggest a reasonable point of intervention for struggling students. A measure of agentic engagement, which describes the extent to which a student exerts agency to personalize a learning experience, could add value to measures of engagement, especially in OWI where actions and agency are integral to student success. In addition, a focus on engagement and intervention/remediation may offer an opportunity for students to succeed in learning online, not just in OWI, which is a valued skill in the workplace.
\end{abstract}

\section{Keywords}

Online Writing Instruction, OWI, Online Education, Distance Education, Engagement, Self Determination Theory, Agency, Writing Pedagogy

This is the author's manuscript of the article published in final edited form as:

Stella, J., \& Corry, M. (2016). Intervention in Online Writing Instruction: An Action-theoretical Perspective. Computers and Composition, 40, 164-174.

https://doi.org/10.1016/j.compcom.2016.03.010 


\section{Introduction}

In this paper, we explore an action-theoretical model of engagement comprised of cognitive, behavioral, emotional, and agentic engagement where agentic engagement may add to the predictive power of Self-Determination Theory (Ryan \& Deci, 2000) in both online education and writing instruction. Agentic engagement may help clarify power and control in the classroom as well as contribute to an understanding of how student voices are heard, which can help teachers and administrators understand student experiences and perspectives (Reeve and Tseng, 2011, Yazzie-Mintze, 2010). Because online education and student reading/writing are highly agentic actions, both measurement and application of agentic engagement in online writing instruction are important to student success. The actiontheoretical model, with its action perspective, suggests that the most successful interventions occur where variables affecting student outcomes are alterable (Fredricks, Blumenfeldt, \& Paris, 2004). To this end, an action-theoretical model of engagement may facilitate successful interventions in online writing instruction by providing an early warning system, framing effective interventions, and supporting "learning to learn" in online education.

\section{Engagement in the action-theoretical model of SDT}

\subsection{Self-determination theory: Motivation, engagement, and actions}

Self-Determination Theory (SDT) is a framework through which educators may be able to reliably predict the motivation a student feels toward academic tasks. According to SDT, humans are active and growthoriented organismic creatures; therefore, human actions are inclined toward satisfying three fundamental growth-oriented needs: autonomy (the need to control oneself and one's destiny), competence (the need to feel effective in the social and physical world), and relatedness (the need to belong) (Deci and Ryan, 1985, Deci and Ryan, 2000, Ryan and Deci, 2000). Humans are motivated to satisfy these needs through actions of varying intensities, measured by engagement.

Engagement in SDT describes the nature and intensity of actions that mediate human contexts and outcomes. In fact, a research study by Connell and Wellborn (1991) found engagement to be the mediator between a student's context and their outcomes. The study originated in the newly developed Self-System Model of Motivational Development in which student engagement was found to be optimized if the three fundamental organismic needs of SDT (autonomy, competence, and relatedness) are met. This finding was later supported by other researcher studies including Appleton et al., 2006, Fredricks et al., 2004, Furrer and Skinner, 2003, Patrick et al., 1993, Skinner and Belmont, 1993, Skinner et al., 2009a, Skinner et al., 2009b; and Reeve \& Tseng, 2011.

Fundamental needs in an action-theoretical model of SDT are satisfied through human actions. Human actions in SDT are not simply behaviors; instead, they are defined though an action perspective (Brandtstadter, 1998), which suggests they are part of a larger motivational system that includes the agent (i.e., the self), the intentional behavior (the action), the desired end (the goal), and a way to mediate between the agent and the goal (Skinner et al., 1988a, Skinner et al., 1988b). Therefore, a human action is a behavior (a physical gesture) plus the emotions, intentions, and goals associated with it (Skinner et al., 2008, Skinner et al., 2009b, Skinner et al., 2009a, Skinner and Pitzer, 2012). Take, for example, the behavior of two students raising a hand during class. They are exhibiting the same observable behavior, yet one student's goal could be to add to the class discussion, while another's could be to obtain permission to leave the room. The construct of action allows a distinction between 
these same behaviors. Thus, according to SDT, engagement manifests in action and is driven by fundamental human needs. There are other motivational theories besides SDT (Wigfield, Eccles, Roeser, \& Schiefele, 2008a), but they all have, as a set of target actions, descriptors of engagement, so it could be said that some type of engagement is present in all motivational theories, even when not specified (Skinner et al., 2009).

\subsection{Online education: Actions and engagement}

The actions of the SDT model play an especially large role in online education, but their definition is less clear than in face-to-face education. In online education, observable intentional behavior may be particularly high compared to observable unintentional behavior. For example, logging on to a learning management system (LMS), downloading a document, submitting a document for review, and posting to an online discussion board are all observable, intentional actions; however, the student emotions about the actions are unobservable and, thus, unclear. In addition, it is unclear whether course-related nonverbal behaviors such as hand gestures, tone of voice, or body movements meet the definition of an action because they are not observable even though there may be course-related emotions, intentions, and goals associated with them. For example, in the case of an online student failing to submit an assignment to the class Dropbox, the emotions, intentions, and goals associated with this action can be less obvious than when a student in a face-to-face course comes to class with incomplete homework. According to SDT, the behaviors in the online course would be actions, but fewer of their attributes are known. These ambiguities can make intervention difficult, and the extent to which online learning strains (or even invalidates) the action-theoretical nature of an SDT model is unclear.

\subsection{Online writing instruction: Agency and engagement}

While student academic engagement can be defined as the quality of participation in academic work, agency can be seen as the potential for achieving this level of quality. Indeed, agency can be viewed from the social cognitive perspective as "the capacity to exercise control over one's own thought processes, motivation, and action" (Bandura, 1989, p. 1175). Hence, agentic behavior describes the way in which humans intentionally, and with forethought, regulate and reflect on their behavior (Bandura, 2001). Agency may play an especially large role in online education because agentic behavior is particularly high, while unintentional communication is particularly low. In fact, nearly all communication in online learning takes place as an action through which a student conveys agency with intentional and purposeful behavior (Bandura, 1977, Kuutti, 1995, Mantovani, 1996).

If online learning is agentic, it follows that OWI must be especially agentic, because students exert a high degree of control over their choices (topics, genres, digital tools, etc.) in reading and writing instruction (Basharina, 2009, Lindgren and McDaniel, 2012, Schunk, 2003, Schunk and Schwartz, 1993, Schunk and Zimmerman, 2007, Zimmerman and Bandura, 1994). From the perspective of Michael G. Moore's Theory of Transactional Distance (1993) where dialog describes interactions among teacher, learner, and curriculum, "Dialog is purposeful, constructive, and valued by each party" (Moore, 1993, p. 24). In other words, dialog is agentic in nature. 


\section{Intervention and remediation in OWI}

\subsection{The effect of alterable variables}

Research on the role of engagement for struggling students in online and face-to-face education often focuses on predicting which students may struggle, identifying quickly those who do have trouble, and implementing interventions to re-engage and support students. Even though it may be academically interesting to identify all reasons why a student succeeds or fails at school, alterable variables, in particular, are likely to be most valuable to educators because this is information they can actually use for intervention (Skinner et al., 2009b, Skinner et al., 2009a).

Finn and Voelkl (1993) undertook an effort to identify and use alterable variables for intervention in a motivational system study of at-risk eighth graders in public schools across the country. The study resulted in a list of factors predictive of high school completion, which was then separated into status predictor variables and alterable variables. Status predictor variables were unchangeable, such as socioeconomic status (SES) of the community, student ethnicity, and gender. Alterable variables, on the other hand, were behavioral engagement indicators and institutional policy variables, such as preparation for class (behavioral) and rigid rule systems in the school (institutional). Alterable variables were identified because they were considered amenable to change or more readily influenced by the student's context of teachers, families, and peers. Positive outcomes of the study were significantly lower absenteeism and better classroom participation (also validated by Sinclair, Christenson, Lehr, \& Anderson, 2003). This practice appeals to researchers interested in the influence of student context and self-management systems (such as time management and organization) (Skinner et al., 2008) as well as practitioners, who may prefer to concentrate their efforts on factors within their control (see Rosenthal, 1998). Alterable variables are fewer in number in an online course when compared to a face-to-face course. Consider the physical classroom, which is a teacher-alterable facilitator variable. The teacher can ensure the actions that take place in that atmosphere are enjoyed in a friendly, ordered, and comfortable place for students. Online learning, by contrast, can be consumed from anywhere-such a place as distracting as a loud train station to a relatively calm and quiet office. Thus, the teacher has little opportunity to alter the student's physical environment and make it more conducive to learning. Through the lens of SDT, online education appears to operate on less precisely defined actions and offer fewer alterable variables, so it would offer different opportunities for identifying and quantifying engagement. Most researchers agree that learning is not possible without student engagement (Skinner \& Pitzer, 2012), so understanding student and teacher control over engagement is magnified.

\subsection{The construct of agentic engagement}

Considering the outsized role of agency in $\mathrm{OWI}$, it seems logical that any engagement measure that facilitates intervention and remedial action must consider the contribution of agency to engagement. As such, recent research outcomes from a study by Johnmarshall Reeve and Ching-Mei Tseng (2011) may have combined the two in a way that can be useful in OWI. Reeve and Tseng developed a model of student academic engagement that is comprised of cognitive, behavioral, emotional, and agentic engagement. Most recent research in the measurement of student engagement confirms that models of cognition, behavior, and emotion are stable and empirically validated, but the addition of agentic engagement is new and has specific implications for agency in OWI. 
In both the empirically validated model and Reeve and Tseng's model, cognitive, behavioral, and emotional engagement are defined similarly. Cognitive engagement is meant to measure the degree to which students use their own specific learning strategies in a learning situation. Behavioral engagement measures persistence, attention, and active effort to stay on task. Emotional/affective engagement measures a learner's attitude toward the learning task, mood, and enthusiasm (Fredricks et al., 2004, Reeve and Lee, 2013). Agentic engagement describes the extent to which a student asserts agency to intentionally, constructively, and proactively try to personalize the content, conditions, and circumstances of their learning experience. Unlike cognitive, behavioral, or emotional engagement, agentic engagement does not flow one way from the student. Instead, agentic engagement measures the extent to which the receiver of an action modifies their response, and the communication continues in a circular way. As such, an instructor may modify the teaching style from controlling to autonomysupportive in response to a student's attempt to personalize, enrich, or otherwise constructively modify the learning experience dialectically (Reeve, 2013, Skinner and Belmont, 1993).

Agentic engagement has been used in a variety of studies about traditional brick-and-mortar students (Cheon et al., 2012, Eren, 2013, Reeve, 2013, Reeve and Tseng, 2011), but it may not be well known in online education. In OWI, measuring agentic engagement could clarify how online student voices are heard and how students exercise constructive control over learning processes, which may provide a better picture of how students really act, interact, and engage in the online classroom.

\section{The application of agentic engagement in OWI}

Measures of engagement are key to successful interventions. They are widely accepted by educators as both useful and actionable information. According to the research we have reviewed in this article, instructors can be effective in both their interventions and remediation by focusing their time on activities correlated with alterable variables (Finn and Voekel, 1993; Sinclair et al., 2003). In addition, adding agentic engagement to the cognitive/behavioral/emotional model may specialize engagement for OWI or for online courses in general where agentic behavior is particularly prevalent. Unfortunately, however, translating these theories into pedagogical actions can be problematic. For one thing, theorists caution against using a single "right" way to improve student motivation (Pintrich, 2003) or trying to match a type of engagement against a particular activity because there are overlapping areas of student academic engagement, and the nomenclature is still developing (Appleton et al., 2008, Christenson et al., 2012, Pintrich, 2003, Skinner et al., 2009b, Skinner et al., 2009a). As well, a list of alterable variables based on actions in OWI, or online education in general, has yet to be developed. Even so, actions based on this research could facilitate the following advantages: (a) more effective early warning and firstresponse systems for OWI courses, (b) a supportive framework in the design of efficient interventions, and (c) effective support for learning to learn in online education.

\subsection{Effective early warning system and first-response}

Engagement measures that register an early warning system for struggling students are especially helpful in OWI courses, and first-response interventions that encourage agentic engagement may reengage students more quickly. An early warning system can be as simple as a pre-course selfassessment of each student's agentic behavior habits, writing skills, and prior experience with online education, which studies have shown to be a predictor of success in online education (Brett, 2004; Carpenter et al., 2004; Sun and Rueda, 2012; Warnock, 2009). Early warning is especially crucial in OWI 
where a student can begin passive withdrawal (Simpson, 2004) and disengagement from a class long before missing an assignment, which is an observable action and a common intervention point. Indeed, by the time an OWI teacher suspects difficulty, a student could be fully disaffected and much more difficult to re-engage. Passive withdrawal is especially troublesome in an OWI class where writing assignments are built from draft to draft, making it easier to fall behind. Passive withdrawal in OWI could signal a "thrive and dive" behavior observed in research findings from Sapp and Simon (2005) where undergraduate OWI students either completed the course with high grades or failed the course entirely, or it could be related to difficulty with time management, technology issues, or even typing skill (which, in our experience, hinders a surprising number of students). Measures of student engagement could offer an opportunity for intervention before a student reaches the "dive" stage. To enhance this early warning system, OWI teachers might consider collaborating with other teachers to document common early warning indicators, especially those observed in thrive/dive situations. In face-to face courses, this collaboration was suggested by Frazelle and Nagel (2015) as a way to keep a record of early warning indicators and interventions that were implemented to track their effectiveness.

In response to an early warning system, agentic intervention strategies in OWI can help re-engage students by supporting their specialized needs. Research indicates that teachers respond to student disaffection with a withdrawal of support and/or increasingly coercive behavior, which can worsen the situation (Skinner \& Pitzer, 2012). If teachers can consider engagement as a "habit of being" rather than a personality trait or a reflection of their teaching skills, it may be easier to react to disaffection with empathy and meaningful support (Furrer and Skinner, 2003, Sinclair et al., 2003, Skinner and Pitzer, 2012). To encourage agency in re-engagement, a teacher can contact the student proactively (Simpson, 2004) and learn what is the nature of the student's disaffection, then personalize the intervention accordingly and offer appropriate autonomy support (Reeve, Jang, Carrell, Jeon, \& Barch, 2004).

Even pre-early warning systems strategies can encourage agency in online writing students. Indeed, it is preferable to plan ahead for variability in individual students instead of creating specialization as a course progresses (Meyer et al., 2014, Oswal, 2015). A Position Statement of Principles and Example Effective Practices for OWI, Principle 1 states, "Online writing instruction should be universally inclusive and accessible" (CCCC OWI Committee, 2013, Hewett, 2015, p. 38). Accessibility is described in the context of students with learning disabilities, and inclusion is described in the context of non-traditional or underserved students; however, strong student preferences can affect learning as well, especially for first-time online students. Providing multimodal course content is recommended to facilitate accessibility and inclusion, and it supports planning for variability as well, which benefits all learners (Hewett \& DePew, 2015). For example, OWI is a text-heavy endeavor. Thus, students with visual impairments will likely use accessible technology, such as a screen reader; however, students without visual impairments usually do not have access to screen readers, but they may prefer to hear text being read to them rather than reading it. Offering an audio version or audio/textual version of text-based lectures (or even a version with pictures) can lower anxiety for students with strong learning preferences for content other than text. Anxiety can lower learning potential and motivation, preventing students from expressing agency through engagement with learning material. Indeed, according to Meyer and Rose (2005), "students for whom printed text is just not an optimal medium can also become disaffected in a print-centric classroom. These students may flourish when provided with other presentational and expressive options, such as multimedia or the arts" (p. 3). In our own work, we have found the CAST UDL Book Builder an excellent option for quick and easy screen-reading capabilities. In 
addition, SoftChalk <http://softchalk.com/> is a development platform that we found fairly easy to master, which also provides the ability to create lectures with text-to-voice options (with an add-on) as well as the ability to easily create formative assessments in many formats to support individual variability in students. A 30-day free trail is offered on the Softchalk website.

\subsection{Effective interventions}

Interventions grounded in SDT and developed in response to alterable variables can be an effective use of a teacher's time and effort in OWI because they enable teachers to alter their autonomy supports for individual students to facilitate the development of their own inner motivational resources. For example, a teacher might support the development of writing competency by requesting more drafts from a student struggling with grammar, or a teacher might suggest supportive $L 2$ technology to English language learning students. In OWI, a LMS can allow multiple assignment submissions and offer grammar/spelling/language supports discretely, which protects the privacy and dignity of individual students. As a pre-intervention strategy, an instructor may consider separating the assessment of researching and organizing content (invention and arrangement) from grammar mechanics (style) throughout the semester, even marking them in different documents. This might be especially useful in expository writing. That way all students, especially English language learners and students who struggle with grammar may gain confidence from the assessment of their other abilities and benefit from grammar scaffolds throughout the semester.

Electronic discussion board activity, especially, may benefit from effective interventions. In fact, research outcomes suggest that moderation/facilitation is needed in online discussions to push conversations beyond agreement and affirmation, which can often be a comfort zone for less experienced online learners (Kanuka, 2011, Kanuka et al., 2007). These surface-level discussions are often characterized by an initial post followed by several "I agree" responses. They can be addressed by personalizing a discussion, or enlarging a conversation to include more content/students. Following is a list of discussion board interventions that are supported by research or that we have found successful in teaching online. This is by no means an exhaustive list, and many instructors may find they instinctively use agentic interventions in OWI simply because they work. In fact, we often reflect on interventions that work particularly well in OWI, and it seems quite apparent how agentic engagement influenced the outcomes.

- Require a short biography of each student, and use it to encourage student agency by bringing the student's experiences, interests, preferences, choices, and curiosity into the discussion. A picture/avatar can be requested as well for further personalization (Mason, 2011, Reeve et al., 2004).

- If students are discussing the same things on different posts, refer them to the other by name. If students interact with each other, they will be more invested in the discussion board (Mason, 2011).

- Use discussion board facilitation as an opportunity to model quality in writing (Warnock, 2009) and quality in discussion participation. In our experience, students will often notice the cadence of instructor posts, and use it as a model for their own responses. For example, if the instructor reply begins with, "Thank you for your thoughtful ideas about public writing and social media, Andrea...," students will often duplicate this beginning in their own responses. As well, results from a study by Shea and Bidjerano (2009) suggested students develop a more confident 
cognitive presence on the discussion board when it is actively facilitated by the instructor because it provides a model for behavior.

- Ask a question of a particular student, and then open the question to all students. ("What do you think of that?" "If anyone else has used this, post your experience, so we can all learn from it"). Enlarging the question may help prevent the students from thinking that some answers are more correct than others, which can happen in a facilitated online discussion (Mason, 2011).

- Some research studies suggest that activities associated with case-studies and debates are particularly useful in encouraging higher-order learning in online education, but students may hesitate to challenge one another. Instructor intervention may be necessary to encourage student agency by clarifying points of view or presenting possible opposing ideas (Kanuka, 2011, Kanuka et al., 2007).

- Ask students to list ideas, examples, or solutions from their own experience, and then keep a combined list in another post citing each student by name after their contributions. This is an effective way to acknowledge student contributions as well as creating a running list for future student reference.

- Change the title of the reply to draw in more readers/writers and add variety to the board. That way, a student can see where their ideas may fit just by scanning the board. In our experience, students will begin using this practice as well after the instructor models it.

Judicious instructor facilitation can nurture student inner motivational resources, which support gradual autonomy on a discussion board; however, instructors must be alert for unexpected results, such as progressively fewer and shorter posts by students (Mazzolini \& Maddison, 2003).

\subsection{Effective support of learning to learn in online education (metacognition)}

Agentic engagement is required for the metacognitive task of revising and collaborating on a written text and reflecting on one's own learning (Sitko, 1998). Unlike writing courses in which printed documents are exchanged for feedback, comments in OWI are digital and textual (Hewett, 2010). Comments may remain in the document while the writer builds an argument from draft to draft, so they can self-evaluate their process. Students can even comment on comments, creating a two-way exchange. In a peer-reviewed document, an instructor can easily see what parts of the critique were integrated into the next draft (Hewett, 2010, Warnock, 2014). This ongoing conversation provides teachers and students with a purposeful, constructive, valued, and readable dialog, which is characteristic of agentic engagement. Though digital dialog is not exclusive to OWI (Purcel, Buchanan, \& Friedreich, 2013Purcell et al., 2013), it is necessary to OWI, which would not be possible without digital writing tools. Agentic engagement is also required in metacognitive intervention strategies, such as tutoring (Frazelle \& Nagel, 2015) and peer review (Hewett, 2010, Warnock, 2009).

Another possible opportunity for learning to learn online may be for students to learn to present material to an audience using technology as a mediator. A possible summative project for OWI students to encourage the development of agency in developing writers might be to research material on a topic of their choice, to be presented in a synchronous online meeting with a text-based question/answer period following. Most students have some anxiety about in-class public speaking, but in our experience, these same students feel more positive and less anxious about using technology to mediate their presentation using slides and their computer. A positive experience with an online presentation such as this can act as a scaffold for future in-person presentations through confidence gained, and the 
question/answer period offers them a chance for agentic engagement where students and the presenter direct the conversation.

Agentic engagement may also be facilitated in an intervention triggered by issues with student selfregulation in the OWI course. These self-regulation supports could be:

- For a student struggling with time management and meeting deadlines, a teacher could add structure to an assignment by requiring multiple check-in milestones before a due date.

- To model time management and increase a sense of belonging, a teacher might assign a student mentor who will contact a struggling student proactively and offer to exchange drafts for informal peer review.

- To build a sense of academic resilience, a teacher might offer opportunities for individual students to recover from failures, such as revising and re-submitting papers.

An OWI teacher should not hesitate to offer tips for online learning success throughout the course and use low-risk/low-stress opportunities to ensure everyone is comfortable with the LMS. For example, a short online quiz on the content of the syllabus may sound too easy, but it requires the student to download or view the syllabus and take an online test-two important skills in any LMS. Similar tasks of small point value to the course can be carried out for turning in work and using an online discussion board. If students can physically try these tasks before deadlines are looming, their increased confidence may enable better quality engagement.

If agentive engagement is, indeed, a new and distinct way to more precisely measure engagement, online education may benefit from measuring. It may be considered in effective early warning and firstresponse systems, as a supportive and efficient framework for interventions, and as an assessment of metacognition for students to reflect on.

\section{Areas of critique and query}

Areas of concern and future query about the use of agentic engagement measurements in online education, especially online writing instruction, remain. They include:

- A research study similar to Finn and Rock (1997), Finn and Voelkl (1993) and Skinner et al. (2009a) is needed to list and analyze the observable actions in online education.

- Research studies about student academic engagement are numerous, but few address domainspecific engagement and autonomy support, such as math engagement, science engagement, reading engagement, etc. (Crippen, Archambault, \& Kern, 2013; Kim et al., 2014; Kong et al., 2003, Wigfield et al., 2008b). More research is needed in instruments to measure engagement in domain-specific online courses (Fredricks and McColsky, 2012, Su and Reeve, 2011).

- How can online teachers discern between engagement and compliance in OWI, especially when a student meets deadlines and scores satisfactorily on assessments. In other words, the student behavior appears engaged, but the instructor does not know the student is emotionally disaffected (Patrick et al., 1993, Skinner et al., 2009a). How can online teachers discern between disaffection and anxiety (Finn, Pannozzo, \& Voelkl, 1995)?

- Adding a new construct, such as agentive engagement, to the cognitive/behavioral/emotional model of engagement likely affects the relationships among the constructs significantly (Betts, 
2012). How does this manifest in online classes that require more student agency, like OWI, compared to classes that may require less, such as mathematics?

- How does agentic engagement differ in synchronous and asynchronous courses or online discussions (Brett, 2004, Mason, 2011, McBrien et al., 2009, Skinner, 2009)?

- What is the best use of interventions in online writing instruction (Hewett, 2010, Stella and Corry, 2013)?

- What empirical research designs may be more successful when studying online engagement (Bernard, Abrami, Lou, \& Borokhovski, 2004)?

\section{Conclusion}

Academic engagement from an action perspective can be a responsive and malleable construct that creates an environment where all students can be successful, not just students with particular contexts and abilities (Klem and Connell, 2004, Skinner et al., 2008, Pintrich, 2003). Indeed, where online learning was once recommended especially for students who were independent learners, intrinsically motivated, or self-starters, we now find education technology ubiquitous in society, and all students should have an equal opportunity to learn how to use it. In fact, Susan Lowes (2013) observed that online education research may be turning away from screening out students without particular personality/success traits or motivational styles and increasingly toward growing all students into successful online learners through experience. At any rate, with the rapid growth of online learning, it is likely students of all abilities will try online education at some point. Instead of requiring particular learner traits or contexts, online instructors and course designers could focus instead on engagement factors (cognitive, behavioral, emotional/affective, and agentic) that may be independent of learner traits or contexts. This focus is a way of using online learning to "meet them where they are" and provide intervention, support, and remediation to ensure student success. Perhaps a focus on engagement, and especially agentic engagement, may provide insight to online learning in general. Online writing instruction, where student agency is inherently high, may particularly benefit from the action perspective as an early warning system for interventions or as a guide for effective interventions and "learning to learn" in online education. Although much is still unknown about the role of agentic engagement in OWI, a model of engagement that includes agentic engagement is a possible approach. 


\section{Acknowledgements}

Special thank you to Jennifer Veltsos, Associate Professor of technical communication at Minnesota State University. 


\section{Authors}

Julie Stella is a researcher at the Center for the Advancement of Research in Distance Education (CARDE) at George Washington University in Washington, DC where she also teaches graduate courses in Education Technology. Ms. Stella holds an MA in Professional Writing from Minnesota State University, and she has over 10 years of experience as a software engineer and developer.

Michael Corry is Director of the Center for Advancement of Research in Distance Education (CARDE) at the George Washington University in Washington, DC where he is also an Associate Professor of Educational Technology. Dr. Corry's research interests include distance learning and other educational technologies. He has numerous publications and presentations involving his research interests including four books. He holds a PhD from Indiana University. 


\section{References}

Appleton, James J., Christenson, Sandra L., \& Furlong, Michael J. (2008). Student engagement with school: Critical conceptual and methodological issues of the construct. Psychology in the Schools, 45(5), 369-386.

Appleton, James J., Christenson, Sandra L., Kim, Dongjin, \& Reschly, Amy L. (2006). Measuring cognitive and psychological engagement: Validation of the student engagement instrument. Journal of School Psychology, 44(5), 427-445.

Bandura, Albert. (1989). Human agency in social cognitive theory. American Psychologist, 44(9), 11751184.

Bandura, Albert. (1977). Self-efficacy: Toward a unifying theory of behavioral change. Psychological Review, 84(2), 191-215.

Bandura, Albert. (2001). Social cognitive theory: An agentic perspective. Annual Review of Psychology, $52,1-26$.

Basharina, Olga. (2009). Student agency and language-learning processes and outcomes in international online environments. CALICO Journal,26(2), 390-412.

Bernard, Robert M., Abrami, Philip C., Lou, Yiping, \& Borokhovski, Evgueni. (2004). A methodological morass? How we can improve quantitative research in distance education. Distance Education, 25(2), 175-198.

Betts, Joseph. (2012). Issues and methods in the measurement of student engagement: Advancing the construct through statistical modeling. In Sandra L. Christenson, Amy L. Reschly, \& Cathy Wiley (Eds.), Handbook of research on student engagement (pp. 783-803). New York: Springer.

Brandstadter, Jochen. (1998). Action perspectives on human development. In Handbook of Child Psychology: Vol. 1. Theoretical Models of Human Development (5th edition, pp. 807-863). New York: Wiley.

Brett, Clare. (2004). Offline factors contributing to online engagement. Technology, Pedagogy and Education, 13(1), 83-95.

CCCC OWI Committee for Effective Practices in Online Writing Instruction. (2013). A position statement of principles and effective practices for online writing instruction (OWI).. Retrieved July 2015, from http://www.ncte.org/cccc/resources/positions/owiprinciples

Cheon, Sung Hyon, Reeve, Johnmarshall, \& Moon, Ik Soo. (2012). Experimentally based, longitudinally designed, teacher-focused intervention to help physical education teachers be more autonomy supportive toward their students. Journal of Sport and Exercise Psychology, 34,365-396.

Christenson, Sandra L., Reschly, Amy L., \& Wiley, Cathy. (2012). Epilogue. In Sandra L. Christenson, Amy L. Reschly, \& Cathy Wiley (Eds.), Handbook of research on student engagement. New York: Springer.

Connell, James P., \& Wellborn, James G. (1991). Competence, autonomy, and relatedness: A motivational analysis of self-system processes. In R. Megan, Alan. Gunnar, \& L. Sroufe (Eds.), Self-processes and development. The Minnesota Symposia on Child Psychology (pp. 44-77).

Crippen, Kent J., Archambault, Leanna A., \& Kern, Cindy L. (2013). The nature of laboratory learning experiences in secondary science online. Journal of Research in Science Education, 43(3), 10291050.

Deci, Edward L., \& Ryan, Richard M. (1985). The general causality orientations scale: Self-determination in personality. Journal of Research in Personality, 19, 109-134.

Deci, Edward L., \& Ryan, Richard M. (2000). The "what" and "why" of goal pursuits: Human needs and the self-determination of behavior. Psychological Inquiry, 11(4), 227-268.

Eren, Altay. (2013). Prospective teachers' perceptions of instrumentality, boredom coping strategies, and four aspects of engagement. Teaching Education, 24(3), 302-326. 
Finn, Jeremy D., \& Rock, Donald A. (1997). Academic success among students at risk for school failure. Journal of Applied Psychology, 82(2),221-234.

Finn, Jeremy D., \& Voelkl, Kristin E. (1993). School characteristics related to student engagement. Journal of Negro Education, 62(3),249-268.

Finn, Jeremy D., Pannozzo, Gina M., \& Voelkl, Kristin E. (1995). Disruptive and inattentive- withdrawn behavior and achievement among fourth graders. Elementary School Journal, 95(5), 421-454.

Frazelle, Sarah, \& Nagel, Aisling. (2015). A practitioner's guide to implementing early warning systems. In National Center for Education Evaluation and Regional Assistance, Institute of Education Sciences. Washington, DC: U.S. Department of Education.

Fredricks, Jennifer A., \& McColsky, Wendy. (2012). The measurement of student engagement: A comparative analysis of various methods and student self-report instruments. In Sandra L. Christenson, Amy L. Reschly, \& Cathy Wiley (Eds.), Handbook of research on student engagement (pp. 763-782). New York: Springer.

Fredricks, Jennifer A., Blumenfeldt, Phyllis C., \& Paris, Alison H. (2004). School engagement: Potential of the concept, state of the evidence. Journal of Educational Research, 74(1), 59-109.

Furrer, Carrie, \& Skinner, Ellen A. (2003). Sense of relatedness as a factor in children's academic engagement and performance. Journal of Educational Psychology, 95(1), 148-162.

Hewett, Beth L. (2015). Grounding principles of OWI. In Beth L. Hewett, \& Kevin E. DePew (Eds.), Foundational practices in online writing instruction (pp. 253-289). Anderson, SC, USA: Parlour Press.

Hewett, Beth L. (2010). The online writing conference: A guide for teachers and tutors. Portsmouth, NJ: Boynton/Cook Heinemann.

Hewett, Beth L., \& DePew, Kevin E. (Eds.). (2015). Foundational practices in online writing instruction. Anderson, SC: Parlour Press.

Kanuka, Heather. (2011). Interaction and the online distance classroom: Do instructional methods effect the quality of interaction? Journal of Computing in Higher Education, 23(2), 143-156.

Kanuka, Heather, Roarke, Liam, \& Laflamme, Elaine. (2007). The influence of instructional methods on the quality of online discussion. British Journal of Educational Technology, 38(2), 260-271.

Klem, Adena M., \& Connell, James P. (2004). Relationships matter: Linking teacher support to student engagement and achievement. Journal of School Health, 74(7), 262-273.

Kong, Qi-Ping, Wong, Ngai-Ying, \& Lam, Chi-Chung. (2003). Engagement in mathematics: Development of instrument and validation of construct. Mathematics Education Research Journal, 15(1), 4-21.

Kuutti, Kari. (1995). Activity theory as a potential framework for human-computer interaction research. In Bonnie Nardi (Ed.), Context and consciousness: Activity theory and human-computer interaction (pp. 17-44). Cambridge, MA: Cambridge MIT Press.

Lindgren, Robb, \& McDaniel, Rudy. (2012). Transforming online learning through narrative and student agency. Educational Technology \& Society,15(4), 344-355.

Lowes, Susan. (2013 October 16). In K. Kathryn (Ed.), Research in review. Learning to learn (Guest Blogger). VA, USA: Vienna.

Mantovani, Guiseppe. (1996). Social context in $\mathrm{HCl}$ : A new framework for mental models, cooperation, and communication. Cognitive Science,20, 237-269.

Mason, Robert B. (2011). Student engagement with, and participation in, an e-forum. Education Technology and Society, 14(2),258-268.

Mazzolini, Margaret, \& Maddison, Sarah. (2003). Sage, guide, or ghost? The effect of instructor intervention on student participation in online discussion forums. Computers and Education, 40, 237-253. 
McBrien, J. Lynn, Jones, Phyllis, \& Cheng, Rui. (2009). Virtual spaces: Employing a synchronous online classroom to facilitate student engagement in online learning. International Review of Research in Open and Distance Learning, 10(3).

Meyer, A., \& Rose, D. (2005). The future is in the margins: The role of technology and disability in education reform.. Retrieved from http://www.udlcenter.org/sites/udlcenter.org/files/MeyerRose FutureisintheMargins.pdf

Meyer, Anne, Rose, David H., \& Gordon, David. (2014). Universal Design for Learning: Theory and Practice. Wakefield, MA: CAST

Moore, Michael G. (1993). Theory of transactional distance. In Michael G. Moore (Ed.), Handbook of distance education (2nd ed., pp. 22-38). Mahwah, NJ: L. Erlbaum Associates.

Oswal, Sushil K. (2015). Physical and learning disabilities in OWI. In Beth L. Hewett, \& Kevin E. DePew (Eds.), Foundational practices in online writing instruction (pp. 253-289). Anderson, SC, USA: Parlour Press.

Patrick, Brian C., Skinner, Ellen A., \& Connell, James P. (1993). What motivates children's behavior and emotion? Joint effects of perceived control and autonomy in the academic domain. Journal of Personality and Social Psychology, 65(4), 781-791.

Pintrich, Paul R. (2003). A motivational science perspective on the role of student motivation in learning and teaching contexts. Journal of Educational Psychology, 95(4), 667-686.

Purcel, Kristen, Buchanan, Judy, \& Friedreich, Linda. (2013 July 16). The impact of digital tools on student writing and how writing is taught in schools. Retrieved from http://www.pewinternet.org/2013/07/16/the-impact-of-digital-tools-on-student-writing-andhow-writing-is-taught-in-schools/

Reeve, Johnmarshall. (2013). How students create motivationally supportive learning environments for themselves: The concept of agentic engagement. Journal of Education Psychology, 105(3), 579595.

Reeve, Johnmarshall, \& Lee, Woogul. (2013 November 11). Students' classroom engagement produces longitudinal changes in classroom motivation. Journal of Education Psychology, 1-14.

Reeve, Johnmarshall, \& Tseng, Ching-Mei. (2011). Agency as a fourth aspect of students' engagement during learning activities. Contemporary Educational Psychology, 36(4), 257-267.

Reeve, Johnmarshall, Jang, Hyungshim, Carrell, Dan, Jeon, Soohyun, \& Barch, Ion. (2004). Enhancing students' engagement by increasing teachers' autonomy support. Motivation and Emotion, 28(2).

Rosenthal, Beth Spenciner. (1998). Non-school correlates of drop-out: A review of the literature. Children and Youth Services Review, 20(5),413-433.

Ryan, Richard M., \& Deci, Edward L. (2000). Self-determination theory and the facilitation of intrinsic motivation, social development, and well-being. American Psychologist, 55(1), 68-78.

Sapp, Dale Alan, \& Simon, James. (2005). Comparing grades in online and face-to-face writing courses: Interpersonal accountability and institutional commitment. Computers and Composition, 22(4), 471-489.

Schunk, Dale H. (2003). Self-efficacy for reading and writing: Influence of modeling, goal setting, and self- evaluation. Reading and Writing Quarterly, 19, 159-172.

Schunk, Dale H., \& Schwartz, Carl W. (1993). Goals and progress feedback: Effects on self-efficacy and writing achievement. Contemporary Educational Psychology, 18(3), 337-354.

Schunk, Dale H., \& Zimmerman, Barry J. (2007). Influencing children's self-efficacy and self-regulation of reading. Reading and Writing Quarterly,23, 7-25.

Shea, Peter, \& Bidjerano, Temi. (2009). Community of inquiry as a theoretical framework to foster "epistemic engagement" and "cognitive presence" in online education. Computers and Education, 52, 543-553. 
Simpson, Ormond. (2004). The impact on retention of interventions to support distance learning. Open Learning, 19(1), 79-96.

Sinclair, Mary F., Christenson, Sandra L., Lehr, Camilla A., \& Anderson, Amy Reschly. (2003). Facilitation student engagement: Lessons learned from check \& connect longitudinal studies. The California School Psychologist, 8, 29-41.

Sitko, Barbara. (1998). Knowing how to write: Metacognition in writing instruction. In Douglas J. Hacker, John Dunlosky, \& Arthur C. Graesser (Eds.), Metacognition in educational theory and practice. New York: Routledge.

Skinner, Ellen A., \& Belmont, Michael J. (1993). Motivation in the classroom: Reciprocal effects of teacher behavior and student engagement across the school year. Journal of Educational Psychology, 85(4), 571-581.

Skinner, Ellen A., \& Pitzer, Jennifer R. (2012). Developmental dynamics of student engagement, coping, and everyday resilience. In Sandra L. Christenson, Amy L. Reschly, \& Cathy Wiley (Eds.), Handbook of research on student engagement. New York: Springer.

Skinner, Ellen A., Chapman, Michael, \& Baltes, Paul B. (1988a). Children's beliefs about control, meansends, and agency: Developmental differences during middle childhood. International Journal of Behavioral Development, 11(3), 369-388.

Skinner, Ellen A., Chapman, Michael, \& Baltes, Paul B. (1988b). Control, means-ends, and agency beliefs: A new conceptualization and its measurement during childhood. Journal of Personality and Social Psychology, 54(1), 117-133.

Skinner, Ellen A., Furrer, Carrie, Marchand, Gwen, \& Kindermann, Thomas. (2008). Engagement and disaffection in the classroom: Part of a larger motivational dynamic? Journal of Educational Psychology, 100(4), 765-781.

Skinner, Ellen A., Kindermann, Thomas A., \& Furrer, Carrie J. (2009). A motivational perspective on engagement and disaffection: Conceptualization and assessment of children's behavioral and emotional participation in academic activities in the classroom. Educational and Psychological Measurement, 69(3), 493-525.

Skinner, Ellen A., Kindermann, Thomas A., Connell, James P., \& Wellborn, James G. (2009). Engagement and disaffection as organizational constructs in the dynamics of motivational development. In Kathryn R. Wentzel, \& Allan Wigfield (Eds.), Handbook of motivation at school (pp. 223-246). New York: Routledge.

Skinner, Elisabeth. (2009). Using community development theory to improve student engagement in online discussion: a case study. ALT-J, Research in Learning Technology, 17(2), 89-100.

Stella, Jsulie, \& Corry, Michael. (2013). Teaching writing in online distance education: Supporting student success. Online Journal of Distance Learning Administration, 16(2).

Su, Yu-Lan, \& Reeve, Johnmarshall. (2011). A meta-analysis of the effectiveness of intervention programs designed to support autonomy. Education Psychology Review, 23(1), 159-188.

Warnock, Scott. (2014 August 5). Online peer review writing groups.. Retrieved from http://onlinewritingteacher.blogspot.com/

Warnock, Scott. (2009). Teaching writing online: Why and how. Urbana, IL: National Council of Teachers of English.

Wigfield, Allan, Eccles, Jacquelynne S., Roeser, Robert W., \& Schiefele, Ulrich. (2008). Development of achievement motivation. In William Damon, Richard M. Lerner, Deanna Kuhn, Robert S. Siegler, \& Nancy Eisenberg (Eds.), Child and adolescent development: An advanced course (pp. 406-425). Hoboken, NJ: Wiley \& Sons.

Wigfield, Allan, Guthrie, John T., Perencevich, Ana Taboada, Lutz, Susan K., Mcrae, Angela, \& Barbosa, Pedro. (2008). Role of reading engagement in mediating effects of reading comprehension instruction on reading outcomes. Psychology in the Schools, 45(5), 432-445. 
Yazzie-Mintze, Ethan. (2010). Charting the path from engagement to achievement: A report on the 2009 high school survey of student engagement. In Indiana University, High School Survey of Student Engagement. Bloomington, IN: Center for Evaluation \& Education Policy.

Zimmerman, Barry J., \& Bandura, Albert. (1994). Impact of self-regulatory influences on writing course attainment. American Educational Research Journal, 31(4), 845-862. 